\title{
Irritable bowel syndrome in general practice: prevalence, characteristics, and referral
}

\author{
W G Thompson, K W Heaton, G T Smyth, C Smyth
}

\begin{abstract}
Background and aims-Little is known about the prevalence, symptoms, diagnosis, attitude, and referral to specialists of patients with irritable bowel syndrome (IBS) in general practice. This study aimed to determine these characteristics. Methods-3111 patients attending 36 general practitioners (GPs) at six varied locations in and near Bristol, UK, were screened to identify those with a gastrointestinal problem. These patients $(n=255)$ and their doctors were given questionnaires. Six months later the case notes were examined to reach criteria based diagnoses of functional bowel disorders. Results-Of 255 patients with a gastrointestinal complaint, $30 \%$ were judged to have IBS and $14 \%$ other functional disorders. Compared with 100 patients with an "organic" diagnoses, those with IBS were more often women and more often judged by their GP to be polysymptomatic and to have unexplained symptoms. The majority of patients with IBS $(58 \%)$ were diagnosed as such by the GP; $22 \%$ had other functional diagnoses. Conversely, among 54 patients diagnosed as having IBS by the GPs, the criteria based diagnosis was indeed functional in $\mathbf{9 1 \%}$; only one patient had organic disease (proctitis). More patients with IBS than those with organic disease feared cancer. In most some fear remained after the visit to the doctor. On logistic regression analysis, predictors of referral to a specialist $(29 \%$ referred) were denial of a role for stress, multiple tests, and frequent bowel movements.

Conclusions-Half the patients with gut complaints seen by GPs have functional disorders. These are usually recognised, and few patients are referred. In IBS, cancer fears often remain, suggesting unconfident diagnosis or inadequate explanation. (Gut 2000;46:78-82)
\end{abstract}

Keywords: irritable bowel syndrome; general practice; primary care; gut complaints; functional bowel disease; referral; health care seeking behaviour

Department of

Postgraduate

Education, University

of Bristol, UK

G T Smyth

Correspondence to: Dr W G Thompson, 7 Nesbitt Street, Nepean, Ontario, Canada, K2H 8C4.

Accepted for publication 21 July 1999

Irritable bowel syndrome (IBS) is considered by gastroenterologists to be a "difficult" condition with major psychological and psychiatric components. ${ }^{1-6}$ However, in a survey of English general practitioners (GPs) we found that they consider IBS less troublesome than other chronic, painful conditions. ${ }^{7}$ We wondered whether this difference in perception was related to an additional finding - that the GPs stated that they send very few patients to specialists. ${ }^{7}$ This selected minority of referred patients might well be atypical. This is a disturbing possibility, since it is on referred patients that most thinking, research, and teaching about IBS is based. As specialists, we cannot claim an undistorted understanding of this condition unless we know the characteristics of patients seen in general practice, including those not referred to us. To date, such knowledge is scanty and none has been obtained in a prospective way or using current definitions of the "functional bowel diseases".

The present study was designed to find answers to several questions: How frequently do GPs encounter IBS and other gastrointestinal disorders? How do they diagnose and label the syndrome? What are the attitudes and fears of the patients? How often and why do GPs refer patients with IBS to specialists? Overall, we hoped to obtain new insights into the nature and evolution of IBS, especially when the condition is undistorted by exposure to specialists and hospitals.

\section{Methods}

We aimed to identify and track a representative cohort of patients attending their family doctors (GPs) in central and southern Bristol and its neighboring towns and villages. This area has a population of about 250000 and is served by 154 GPs. To obtain a spread of practice types and patient profiles, we selected six locations for the study: two urban, three suburban, and one rural. All but two of the 38 GPs working in these locations agreed to collaborate. They worked in practices or partnerships of the following sizes: one had one doctor; one had two doctors; two had three doctors; three had five doctors; and two had six doctors. To find out how representative were these practices, we compared them with national figures with respect to the doctors' sex, the proportion of doctors who were licensed trainers, and the proportion who had patients registered as living in a deprived area. These data were obtained from the Local Health Authority (Avon), from the Royal College of General Practitioners, and from General Medical Services Statistics for England and Wales for 1 October 1997, held by the NHS Executive.
From March to August 1995 at least two members of the research team spent 13 or 14 randomly chosen half day sessions in each

Abbreviations used in this paper: GP, general practitioner; IBS, irritable bowel syndrome. 
Table 1 Gastrointestinal diagnoses in 255 patients presenting to general practitioners

\begin{tabular}{|c|c|c|c|}
\hline & No of patients & $\begin{array}{l}\text { Per cent of patients } \\
\text { with "gut problems" }\end{array}$ & $\begin{array}{l}\text { Per cent of } 3111 \\
\text { screened patients }\end{array}$ \\
\hline Functional & 112 & 43.9 & 3.6 \\
\hline Irritable bowel syndrome & 76 & 29.8 & 2.4 \\
\hline Functional constipation & 6 & 2.4 & \\
\hline Functional diarrhoea & 1 & & \\
\hline Functional abdominal bloating & 1 & & \\
\hline Chronic abdominal pain & 3 & 1.2 & \\
\hline Other functional bowel & 9 & 3.5 & \\
\hline Non-ulcer dyspepsia & 9 & 3.5 & \\
\hline Heartburn but no oesophagitis & 6 & 2.4 & \\
\hline Other upper gut symptoms & 1 & & \\
\hline Organic & 100 & 39.2 & 3.2 \\
\hline Gastroenteritis & 24 & 9.4 & \\
\hline Drug induced symptoms & 20 & 7.8 & \\
\hline Oesophagitis & 13 & 5.1 & \\
\hline Inflammatory bowel disease & 12 & 4.7 & \\
\hline Anorectal disease & 7 & 2.7 & \\
\hline Peptic ulcer & 6 & 2.3 & \\
\hline Postsurgery & 6 & 2.3 & \\
\hline Diverticulitis & 4 & & \\
\hline Gallstones & 5 & & \\
\hline Liver disease & 1 & & \\
\hline Unknown & 43 & 16.9 & 1.4 \\
\hline Dyspepsia, not endoscoped & 13 & 5.1 & \\
\hline Heartburn, not endoscoped & 17 & 6.7 & \\
\hline Transient gut symptoms & 10 & 3.9 & \\
\hline Unknown & 3 & & \\
\hline Total & 255 & 100 & 8.2 \\
\hline
\end{tabular}

The diagnoses were established by review of case notes six months after the initial visit.

group practice. Every adult arriving to see their GP was asked by a study nurse for a brief interview. Consenters were shown a card listing in large letters 10 system based symptom categories from which they chose the main reason for coming; also a second problem if they had one.

\section{PATIENT INTERVIEW}

As they emerged from the GP's consulting room, patients who had specified a gastrointestinal complaint were intercepted, and asked for another interview and permission to review the medical record. A study team member then administered a questionnaire concerning demographics, bowel function symptoms, and beliefs. Symptoms included the Manning ${ }^{8}$ and Rome $^{9}$ criteria for diagnosing the IBS and other functional gastrointestinal disorders.

\section{DOCTOR INTERVIEW}

At the end of each session, any GP who had seen a patient with a gut complaint was interviewed by one of us using a questionnaire which concerned the doctor's diagnosis and investigation, and the patient's health care seeking behaviour.

FOLLOW UP

Six months after each patient's index visit, we reviewed their case notes and identified the GP's diagnosis. If this was not explicit, we chose a diagnosis that best fitted the doctor's actions. Also, using all the available evidencemedical record, study questionnaires, and sometimes a call to the patient or GP-we made our own diagnosis of the index complaint. This was a consensus opinion after discussion by at least three of us. Diagnoses of functional disorders were based on the Rome or Manning criteria in which abdominal pain is a requisite for the irritable bowel, ${ }^{89}$ and on our overall judgement. Recorded tests were also noted.

\section{STATISTICS}

Unless otherwise specified, $\mathrm{p}$ values were derived from Mann-Whitney tests for continuous variables and $\chi^{2}$ analysis with the Yates's correction for categorical variables. Logistic regression was used to identify, among all possibly relevant and recorded characteristics, those which predicted specialist referral.

The study was approved by the Ethics Committee of the United Bristol Hospitals Trust.

\section{Results}

REPRESENTATIVENESS OF PARTICIPATING

DOCTORS AND PRACTICES

Of the 36 GPs, 12 were women (33\%); the national figure was $31.5 \%$. The number of our GPs approved as trainers was four $(11 \%)$; the national figure was $12.3 \%$. No practice had special academic status; one doctor was a part time lecturer in the university and one (GTS) was a part time clinical tutor. The number of doctors having patients registered as living in a deprived area was $20(56 \%)$; the national figure was $48.3 \%$ (but the average number of deprived patients per GP was slightly lower than the national one).

SCREENING AND DEMOGRAPHICS

Of 3157 patients approached, 3111 (98.5\%) agreed to the screening interview $(64.5 \%$ women). The number screened in each location ranged from 416 to 712 . Three hundred patients $(9.6 \%$, range $7-10 \%$ per location) said they were attending with a digestive problem. However, 17 did not tell their doctor about it or were found at interview to have misattributed their symptoms to the digestive category, three refused the second interview, and one died.

Therefore, 279 patients were interviewed further. Of these, 22 were judged by their GP and the study team not to have a gastrointestinal complaint after all, one died, and one could not be traced. Thus 255 patients $(8.2 \%$ of all screened patients) were eligible for the study -87 men and 168 (66\%) women, mean age 53 years (range 18-89).

\section{OCCURRENCE OF GUT DISORDERS}

Table 1 lists the gastrointestinal diagnoses, which were the patients' first problem in $76 \%$ and the second problem in $24 \%$. Seventy six patients were judged by us to have IBS $(86 \%$ women, mean age 48 years), and a total of 112 $(44 \%)$ to have a functional gastrointestinal complaint. The data were inadequate to determine whether the condition was functional or organic in $43(17 \%)$ (fig 1). One hundred $(39 \%)$ had a clear "organic" diagnosis $(60 \%$ women, mean age 53 years).

DIAGNOSES, CHARACTERISTICS, AND INVESTIGATIONS OF PATIENTS WITH IBS

Patients with IBS were more often women than were those with organic disease (table 2). All 76 had abdominal pain (by definition) and all but two had two or more of the Manning criteria at 


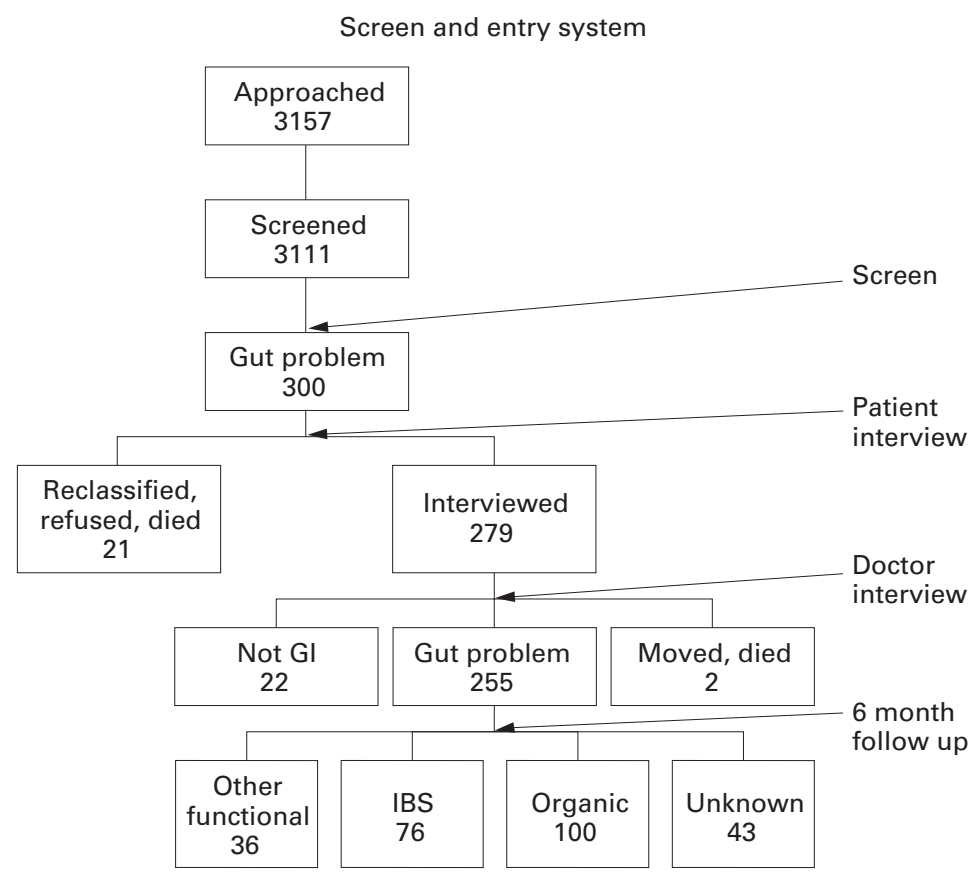

Figure 1 Results of approaching 3157 adults who attended their general practitioners in six English locations and further studying the 255 who had a gastrointestinal problem.

the time of the index visit. Fifty eight $(76 \%)$ fulfilled the Rome criteria. ${ }^{9}$ Eleven (15\%) stated that they had not previously seen a doctor for these symptoms, while $54 \%$ had been attending longer than a year.

The GPs' diagnoses of these 76 cases were IBS or a synonym in $44(58 \%)$, constipation in nine, and other functional gut syndromes in eight (a total of $80 \%$ with a functional gut label). Organic diagnoses were made in six $(8 \%)$ : inflammatory bowel disease in two; and gastro-oesophageal reflux, gastroenteritis, diverticulitis, and colon cancer, each in one patient. The GP's diagnosis was unclear in nine $(12 \%)$.

Among 54 patients diagnosed as having IBS by the GP, we agreed in $44(82 \%)$ and deemed five to have other functional gut syndromes (total functional 91\%). In four the diagnosis was uncertain. One had proctitis.

The GPs considered that more IBS than organic patients had had unexplained symptoms or were polysymptomatic (table 2) and also that these features helped them to

Table 2 Percentage of patients with irritable bowel syndrome (IBS, $n=76)$ and organic disease $(n=100)$ having different characteristics at the index visit

\begin{tabular}{llll}
\hline & IBS & Organic disease & p Value \\
\hline $\begin{array}{l}\text { Doctor's observations } \\
\text { Deemed polysymptomatic }\end{array}$ & 46 & 24 & $<0.004$ \\
$\begin{array}{l}\text { Previous unexplained symptoms } \\
\text { Patient's responses }\end{array}$ & 46 & 17 & $<0.0001$ \\
Fear of serious disease & 55 & 41 & \\
Fear of cancer & 46 & 30 & 0.084 \\
Fear of cancer removed after visit & $29(10 / 35)$ & $41(12 / 29)$ & $\mathrm{NS}$ \\
Entirely better about symptoms after visit & 26 & 49 & $<0.004$ \\
Stress aggravates symptoms & 59 & 42 & $<0.004$ \\
Symptoms for more than six months & 72 & 41 & $<0.0001$ \\
Days off work in previous year & 16 & 24 & $\mathrm{NS}$ \\
Off work for more than 10 days or disabled & 3 & 11 & $<0.03 \star$ \\
Interference with social life & 63 & 54 & $\mathrm{NS}$ \\
Stopped social life & 3 & 16 & $<0.007$ \\
\hline
\end{tabular}

^Fisher's test. distinguish functional from organic disease in $59 \%$ and $54 \%$ of cases respectively.

A colon investigation was recorded in $38 \%$ of patients with IBS $(14 \%$ of 35 patients aged less than 45 years, $58 \%$ of 41 patients aged over 45 years): barium enema in 33\%, sigmoidoscopy in $14 \%$, and colonoscopy in $5 \%$. Blood tests were performed in $21 \%$, ultrasound in $14 \%$, oesophagogastroduodenoscopy in 5\%, occult blood in $5 \%$, barium meal in $11 \%$, and small bowel $x$ ray in $1 \%$. Overall, $63 \%$ of these patients had an investigation of some kind.

During the six months following the index visit, patients with IBS visited the practice more often than did organic patients (5.3 (SD 2.8 ) versus 4.1 (3.8); independent samples $t$ test, $\mathrm{p}=0.054$ ).

ATTITUDES AND PERCEPTIONS OF PATIENTS

Fear of cancer was common in patients with IBS $(46 \%$ versus $30 \%$ in organic disease, p $<0.04$ ). Only $29 \%$ of patients with this fear lost it after seeing the doctor. Only $26 \%$ felt entirely better about their symptoms after the visit (versus $49 \%$ of organic patients, $\mathrm{p}<0.004$ ). The majority of patients with IBS believed that stress aggravated their problem. Patients with IBS had rarely stopped social life completely, and were no more likely than organic patients to have time off work, disability, or interference with social life.

REFERRAL OF PATIENTS WITH IBS

The GPs referred $20 \%$ of patients with IBS to a gastroenterologist or physician and $9 \%$ to a surgeon for gut symptoms (data gathered at the index visit and at the six month follow up). On forward, stepwise, logistic regression the model that best predicted referral (correctly predicting in $85.4 \%$ of cases) included the following: if stress was admitted as worsening the symptoms, the relative risk of referral was $0.35(95 \%$ confidence interval (CI) 0.17 to 0.7 ); with each test this risk rose by 2.14 (95\% CI 1.2 to 3.84 ); if the index visit was the first visit for these symptoms, the risk was 0 (in the next six months); if there were more than three bowel movements per day, the risk was 2.74 (95\% CI 1.36 to 5.54$)$.

\section{Discussion}

The strengths of this study are the on site observations of doctor-patient encounters, the meticulous six months' follow up, and the capturing of virtually all consultations within a defined time span. As English patients must seek medical care through their general practitioner, who also holds their medical record, failure to identify misdiagnoses of serious organic disease is unlikely. Primary contact with doctors may be different in other health care systems. For example, in some countries, patients may consult a specialist without referral. Nevertheless, at first contact patients are likely to have similar characteristics, whether they are seeing a family doctor or a specialist. Therefore, our data permit conclusions about current gastrointestinal disease patterns and their characteristics in primary care. On the 
other hand, the number of cases of individual diseases is small, especially for organic disease, so conclusions must be cautious.

This study confirms that gastrointestinal problems are common in primary care, accounting for about one in 12 consultations, ${ }^{10}$ and shows the range of gut complaints commonly seen by GPs. The key finding is that in nearly half the patients the problem was functional. Indeed, our estimate of $46 \%$ is a conservative one, as more functional cases must be present among the patients with uncertain diagnoses. By far the most common gastrointestinal condition seen by GPs is IBS. From the fact that it took 81 half day sessions to accumulate 76 such patients it can be calculated that, on average, a GP in full time practice is seeing eight patients with IBS a week (one of whom is presenting for the first time).

Despite the frequency of functional gut disorders in a doctor's workload, scanty time is devoted to them in medical training. ${ }^{11}$ How, then, are doctors coping? Firstly, how well do GPs diagnose the syndrome? The answer depends on the importance attached to specific diagnostic labels. The term IBS was applied to only $58 \%$ of the patients who merited it but a further $22 \%$ were given a functional label, so $80 \%$ were correctly called functional. This seems reassuring except that it means $20 \%$ of patients with IBS were left without a clear diagnosis which might have caused concern to some of them. Among the patients diagnosed as having IBS by the doctors, only one had organic disease, which again seems reassuring. However, there were very few new cases of organic gastrointestinal disease in this study (no cancer at all), so no conclusions can be drawn about the safety of GPs' diagnoses of functional disease.

How do GPs reach the diagnosis of IBS? Our data show that it is not by doing tests to exclude organic disease (confirming what a random sample of GPs had told us previously ${ }^{7}$ ). A test minimising policy is adopted by experts in functional bowel disorders too, but they tend to rely on published symptom criteria such as those of Manning et al, ${ }^{8}$ whereas few GPs have heard of them. ${ }^{7}$ GPs must be noticing other characteristics of patients with IBS. Some of these are apparent in our study. The GPs perceived their patients with IBS to be prone to unexplained symptoms, to be polysymptomatic, and to have had gut symptoms for a long timecharacteristics known to predict a functional diagnosis in specialist practice. ${ }^{812} 13$ They may also have noticed, as we did, that the patients visited frequently and were nearly all women.

The IBS observed here seemed to be mild to judge by the low level of work loss and social disablement. This mildness helps to explain our earlier finding that GPs consider IBS a relatively easy condition to cope with ${ }^{7}$ and contrasts with the situation in specialist practice, where the patients tend to report much time off work, ${ }^{14}$ poor quality of life, ${ }^{15}$ and disabling symptoms. ${ }^{16}$ Mild or not, most of the patients with IBS in this study feared their condition was serious or even malignant. Indeed, such fears may well have been the incentive to go to the doctor. ${ }^{17}$ Unfortunately, the fears seem to have been dealt with ineffectively, as we found them to be still present at the end of most consultations (perhaps explaining why the patients came back so often in the follow up period).

Why were the GPs ineffective at removing fear of serious disease? Maybe they failed to elicit it. Another possibility is that they did not provide the patients with a satisfactory disease model in the form of a convincing explanation of IBS. If so, it could have been for lack of time but it could also have been due to lack of understanding of IBS by the doctors themselves. If lack of understanding is indeed part of the problem (as we think likely), then it is up to specialists to develop, with their GP colleagues, ways of explaining IBS to patients in a convincing way.

Only a minority of patients with IBS were referred to specialists (29\%), much as GPs had previously told us. ${ }^{7}$ A major predictor of referral was that the patient denied a role for stress in their symptoms. This finding, similar to one reported elsewhere, ${ }^{16}$ suggests that among the patients whom GPs find difficult to manage are people who recognise no psychological factors in illness. Another predictor of referralfrequent defecation - is readily understood because persistent diarrhoea has serious causes. A third predictor was a long history in that no patient attending for the first time was referred during the six month follow up. This observation implies that it takes time for a "new sufferer" to turn into a "difficult case". It would be useful to know what happens during this time. A possible clue is our finding that the likelihood of referral increased with the number of tests. Repeated testing suggests an unconfident doctor or a patient with persistent fears of organic disease, perhaps one fostering the other. Doing tests is a two edged weapon - as likely to prolong anxiety as to allay $\mathrm{it}^{18}$ - and it deflects attention from the crucial business of teaching the patient the nature of their problem and how to handle it.

In conclusion, this study indicates that GPs manage most patients with IBS without extensive testing or specialist advice. However, the minority of patients who are referred constitute a large workload for gastroenterologists. We suggest that fewer referrals would be needed if GPs gained confidence in the diagnosis by using published symptom criteria and if they developed, perhaps with the help of specialists, convincing explanations of IBS to give patients. Finally, as most patients are managed wholly in primary care, we urge that research into the causes, nature, and treatment of IBS be concentrated there rather than in the secondary care sector.

Dr Thompson was the recipient of a Detweiller grant from the Royal College of Physicians and Surgeons of Canada. The authors are grateful for the support of SmithKline Beecham Pharmaceuticals, Harlow, Essex. Mr A O Hughes kindly assisted with the statistics.

1 Young SJ, Alpers DH, Norland CC, et al. Psychiatric illness and the irritable bowel syndrome. Practical implications for and the irritable bowel syndrome. Practical implications

the primary physician. Gastroenterology 1976;70:162-6.
2 Walker EA, Katon W, Roy-Byrne PP, et al. Psychiatric illness and irritable bowel syndrome: a comparison with inflammatory bowel disease. Am $\mathcal{F}$ Psychiatry 1990;147:156-61. 
3 Walker EA, Roy-Byrne PP, Katon WJ. Irritable bowel syndrome and psychiatric illness. Am $\mathcal{F}$ Psychiatry 1990 147:567-72.

4 Hislop IG. Psychological significance of the irritable colon syndrome. Gut 1971;12:452-7.

5 Lydiard RB, Laraia MT, Howell EF, et al. Can panic disorder present as irritable bowel syndrome. F Clin Psychiatry $1986 ; 47: 470-3$

6 Welch GW, Hillman LC, Pomare EW. Psychoneurotic symptomatology in the irritable bowel syndrome: a study of reporters and non-reporters. BMF 1985;291:1362-4

7 Thompson WG, Heaton KW, Smyth GT, et al. Irritable bowel syndrome: the view from general practice. Eur 7 Gastroenterol Hepatol 1997;9:689-92.

8 Manning AP, Thompson WG, Heaton KW, et al. Towards positive diagnosis of the irritable bowel. BMF 1978;ii: positive

9 Thompson WG, Creed FH, Drossman DA, et al. Functional bowel disorders and functional abdominal pain. Gastroenterol Int 1992;5:75-91.

10 Royal College of General Practitioners, OPCS and DHSS. Morbidity statistics from general Practice 1991-1992. Fourth National Study, Studies on Medical and Population Subjects. London: HMSO, 1995.
11 Thompson WG, Heaton KW, Smyth GT, et al. Gut complaints in general practice: implications for the currculum [abstract]. Gastroenterology 1997;112:A46.

12 Kruis W, Thieme $\mathrm{CH}$, Weinzierl M, et al. A diagnostic score for the irritable bowel syndrome. Its value in the exclusion of organic disease. Gastroenterology 1984;87:1-7.

13 Whorwell PJ, McCallum M, Creed FH, et al. Non-colonic features of irritable bowel syndrome. Gut 1986;27:37-40.

14 Crean GP, Holden RJ, Knill-Jones RP, et al. A database on dyspepsia. Gut 1994;35:191-202.

15 Whitehead WE, Burnett CK, Cook EW, et al. Impact of irritable bowel syndrome on quality of life. Dig Dis Sci 1996;41:2248-53.

16 van der Horst HE, van Dulman AM, Schellevis FG, et al. Do patients with irritable bowel syndrome in primary care really differ from outpatients with irritable bowel syndrome? Gut 1997;41:669-74.

17 Kettell J, Jones R, Lydeard S. Reasons for consultation in irritable bowel syndrome: symptoms and patient characteristics. Br f Gen Pract 1992;42:459-61.

18 McDonald IG, Daly J, Jelinek JM, et al. Opening Pandora's box: the unpredictability of reassurance by a normal test result. $B M F$ 1996;313:329-32. 